\title{
Educação, Interfaces, Saberes Tradicionais e Populares
}

\author{
Heiberle Hirsgberg Horácio ${ }^{1}$ \\ Leonel Piovezana ${ }^{2}$ \\ Mônica Maria Teixeira Amorim ${ }^{3}$
}

O dossiê Educação, Interfaces, Saberes Tradicionais e Populares é uma iniciativa do GDECO-ETNOPO (Grupo de Pesquisa para uma Educação Decolonial PluriEtnoPopular), coordenado pelo professor do PPGE Heiberle Horácio e pela professora do Departamento de Artes Nelcira Durães, composto por mestrandes do PPGE, professoras(es) de grupos "irmãos", como o GEIPI-ABA ${ }^{4}$, e de diferentes departamentos; além de ter como integrante a professora do PPGE Mônica Amorim, uma das organizadoras deste dossiê. O dossiê conta, também, como organizador convidado, com o professor Leonel Piovezana que, além de ser professor do Mestrado em Educação da Unochapecó, é líder do Grupo de Pesquisa SULEAR (Educação Intercultural e Pedagogias Decoloniais na América Latina - Unochapecó), grupo parceiro do GDECO-ETNOPO.

Este dossiê faz parte de um conjunto de ações integradas que constituem o Programa do GDECO-ETNOPO, conjunto de ações que inclui os trabalhos das mestrandas do PPGE que compõem o grupo - Laura Patrícia, Tamires Pereira e João Rosa - , e que inclui os debates para a construção coletiva e colaborativa de uma disciplina na graduação relacionada à "introdução aos pensamentos para educação das relações étnico-raciais, de gênero, sexualidade e interseccionalidade”, que deve ser ofertada para toda a comunidade acadêmica. Ademais, fazem parte das ações que

\footnotetext{
1 Doutor em Ciência da Religião. Professor do Programa de Pós-Graduação em Educação da Universidade Estadual de Montes Claros (Unimontes). Minas Gerais, Brasil. E-mail: conhecimentoindigena@outlook.com. Orcid: https://orcid.org/0000-0002-4486-1764.

2 Doutor em Desenvolvimento Regional. Professor do Programa de Pós-Graduação em Educação da Universidade Comunitária da Região de Chapecó (Unochapecó). Santa Catarina, Brasil. E-mail: leonel@unochapeco.edu.br. Orcid: https://orcid.org/0000-0001-8577-319X.

${ }^{3}$ Doutora em Educação. Professora do Programa de Pós-Graduação em Educação e do Programa de PósGraduação em Desenvolvimento Social da Universidade Estadual de Montes Claros (Unimontes). E-mail: monicamorimsa@hotmail.com. Orcid: https://orcid.org/0000-0002-3537-2686.

${ }^{4} \mathrm{O}$ professor Cássio Alexandre é uma das pessoas que compõem tanto o GDECO-ETNOPO quanto o GEIPI-ABA (Grupo de Estudos com Povos Indígenas na Unimontes), assim como o professor Heiberle. Integram, ainda, o GEIPI-ABA, Carlos Caixeta, Fabiano José e Samylla Alves.
} 
constituem o mencionado programa, os seminários realizados na disciplina Tendências do Pensamento Educacional - ministrada no $1^{\circ}$ e $2^{\circ}$ semestres de 2021 pelos professores Heiberle Horácio e Leandro Luciano. Os seminários na disciplina de Tendências do Pensamento Educacional foram desenvolvidos por diferentes convidades, inclusive indígena, que mobilizaram imprescindíveis questões, como aquelas relacionadas ao Feminismo Negro e ao "movimento negro educador" - com a professora Maria Luiza Higino Evaristo - , aquelas sobre a relação do pensamento de Marx com a Educação Popular (pelo Prof. Gilberto Simplício), aquelas sobre o Neoliberalismo, Desdemocratização e Educação (pelo Prof. Rodrigo Chaves de Mello), aquelas sobre o pensamento de Judith Butler e de Foucault e os processos educativos e educacionais, com os professores Rafael Baioni, integrante do (IN)Serto ${ }^{5}$, e Márcio Sales, respectivamente. A supracitada disciplina contou, ainda, com seminários como o do "Pensamento Decolonial, Educação e Arte", com o professor Eduardo Moura, e sobre Educação do Campo e Pedagogia da Alternância, com o professor Leandro Luciano e com a professora Magda Macedo, professora que, inclusive, deu uma entrevista para este dossiê.

A respeito especificamente do dossiê, ele buscou agregar artigos que compreendessem reflexões sobre os processos educativos e educacionais, também os escolares, suas interfaces como os modos de conhecimento da Literatura e do Cinema e os saberes tradicionais e populares. Consoante com os objetivos do grupo de pesquisa, o dossiê procurou abarcar desde as chamadas Pedagogias Decoloniais (WALSH, 2015) até os "regimes de conhecimento indígenas — não só dos povos originários, ameríndios, mas, também, das comunidades tradicionais —, como também as denominadas, pelo grupo, de alternativas epistemológicas, observando os processos educativos e educacionais do teatro, das religiões, do rito, do cinema, da literatura." (HORÁCIO, 2021).

Desse modo, o dossiê conta com artigos que versam desde a Educação Popular até as compreendidas, pelo GDECO-ETNOPO, como Narrativas Locais de Resistência. Compõe o dossiê artigos de professoras e professores de diferentes instituições, bem como artigos de pesquisadoras e pesquisadores de distintos lugares do Brasil. São eles:

1) As Raízes Epistemológicas do Método Paulo Freire de Alfabetização; dos

\footnotetext{
${ }^{5}$ O (IN)Serto - Núcleo pela Diversidade Sexual e de Gênero atualmente é coordenado pelo Prof. Marcelo Brito.
} 
pesquisadores Jandrei José Maciel, Elcio Cecchetti e Ivo Dickmann;

2) O ensaio como forma e a narrativa como método: encontros com a Teoria Crítica e o feminismo negro; de Rafael Baioni;

3) Reflexões sobre educação indígena na poética de Efraín Miranda; de Ednéia Rodrigues Ribeiro;

4) Saberes em Narrativas de uma comunidade tradicional: oralidade e decolonialidade; de Jarbas Siqueira Ramos e Nelcira Aparecida Durães;

5) "Nova velha história": o mito da cobra grande em Cassiano Ricardo, Raul Bopp e Daniel Munduruku; da pesquisadora Telma Borges da Silva;

6) Estado laico, ensino religioso e intolerância: os desafios da educação pública; de Emerson Sena da Silveira;

7) Rousseau e a educação popular; das pesquisadoras Ana Cristina Armond, Regiani Cristina Jacinto Ferreira e do pesquisador José Benedito de Almeida Júnior;

8) Múltiplas Vozes e Múltiplos Sentidos do Pertencimento Étnico: estudo de remanescentes indígenas Kiriris e Payayás; de Leila Damiana Almeida dos Santos Souza e Kleber Peixoto de Souza;

9) As memórias do PIBID na construção das subjetividades docentes: apontamentos sobre as práticas da história pública ensinada; de Leonara Lacerda Delfino;

10) "Éramos assim, feridos por dentro, mas duros por fora": As pequenas memórias, de José Saramago; de Ana Maria Abrahão dos Santos Oliveira;

11) O conto Pai contra mãe e o filme Quanto vale ou é por quilo?: reflexões filosóficas contra a continuidade do mesmo na educação pública brasileira; de Ildenilson Meireles Barbosa e Wanderley José Cardoso Amorim;

12) A trajetória arqueológica de Michel Foucault: caminhos possíveis; de Márcio Sales.

13) Um estudo da disciplina História da Educação e suas contribuições para a formação docente no Brasil; das pesquisadoras Mônica Soares Rodrigues, Raimara Gonçalves Pereira e Viviane Bernadeth Gandra Brandão.

O dossiê traz, ainda, uma entrevista e duas resenhas. A entrevista sobre 


\section{EdurañangEscolar Socieduce}

Educação do Campo no Semiárido Mineiro contou com as integrantes e colaboradoras do LabÉdoCampoSemiáridoMineiro, as professoras Magda Macêdo, Maria Auxiliadora Amaral S. Gomes (Dodôra), Maria Aparecida A. Oliveira e Roberta Fontes. A entrevista foi realizada pelas mestrandas do PPGE Tamires Pereira e Laura Patrícia, e pelo interlocutor de construção de suas dissertações. Sobre as resenhas, uma é sobre o livro Enquanto Dorme a sua Face, do poeta e educador de Conselheiro Lafaiete, Wagner Vieira; resenha que foi feita pelas pesquisadoras Cristiane Vilhena Lima e Dulce Mary Godinho Pereira. Já a outra resenha, esta sobre o livro Pequeno Manual Antirracista, da professora Djamila Ribeiro, foi feita pelo professor Helyon Lavinas Guimarães.

Por fim, só nos resta agradecer às companheiras professoras e companheiros professores que generosamente enviaram os artigos e confiaram nesta empreitada e que, de algum modo, são companheires do GDECO-ETNOPO, e celebram, nesse ano de 2021, o centenário do nosso igualmente companheiro Paulo Freire. Também nos resta agradecer às leitoras e leitores que generosamente chegaram até aqui; muito obrigado por estarem conosco. Com amor,

Prof. Heiberle Horácio, Profa. Mônica Amorim, Prof. Leonel Piovezana 